\title{
Effect of soil type and footing rigidity on the behavior of nuclear power plants foundation
}

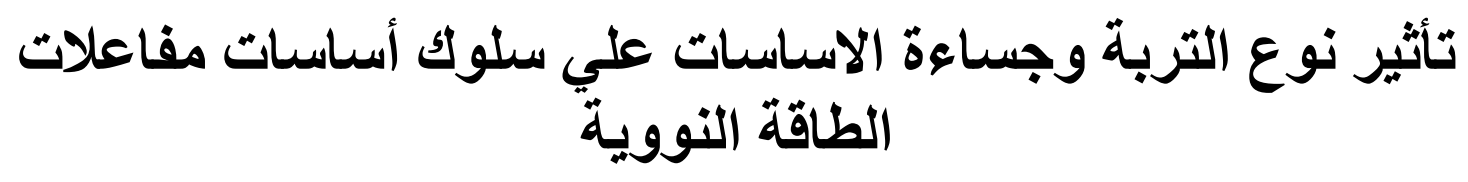

\begin{abstract}
O. Shawky. ${ }^{1}$, Arab. M. G. ${ }^{2}$, El-meliegy M. ${ }^{3}$, Dif A. ${ }^{4}$
${ }^{1}$ Eng. Omar Shawky, B.sc. of Civil Engineering, Faculty of Engineering, Mansoura University, ${ }^{2}$ Dr. Mohamad Gamal Arab, Assc. Prof. of Geotechnical Engineering, Faculty of Engineering, Mansoura University, ${ }^{3}$ Prof. Dr. Mahmoud El-meleigy, Professor of Geotechnical Engineering, Faculty of Engineering, Mansoura University, and ${ }^{4}$ Prof. Dr. Adel Dif, Professor of Geotechnical Engineering, Faculty of Engineering, Mansoura University.
\end{abstract}



\section{ABSTRACT:}

Nuclear power plants are very special structures as a result of their function and their applied loads. Egypt is tending to construct a nuclear power plant contains 4 reactors in Daba'a -north Egypt- to generate electric power. This reactor is the new generation of European reactors which is designed according to British standards. This generation differs from the previous one in the thickness of raft footing. Rock soil is studied as bed rock in this search taking into consideration all soil parameters using 3D model for soil and structure with real dimensions and shape of raft footing in plane. Using (Drucker-Prager) model for soil structure interaction to compute all stresses, strains, and displacements in soil and raft footing after the focus on rock soil due to the existence of different of rock with different strength and cohesion assuming that no fractures, faults, synclines, and anticlines in the bed rock. The raft footing rigidity factors both footing thickness and concrete characteristic strength was analyzed. And finally results present the best suitable conditions for construction of such structure without any problem in soil and raft footing. 


\section{INTRODUCTION}

The subsoil is an integral part of any structure and creates a functional part of it. The interaction of the raft and subsoil has a significant impact on the behavior of the raft and its stability and usability. The careful study of raft and subsoil is very important to the analysis of the soil-structure interaction.

A new generation of nuclear power plants was developed to increase the safety approaches of nuclear plants and to increase the electrical power generated to reach $1600 \mathrm{MW}$ compared to $800 \mathrm{MW}$ for the older generations. The overall design of the new generation of nuclear power plants structures is improved compared to previous nuclear power plants to account for:

i- Internal events: the design of structures are planned to protect the environment against possible leakage of radioactive materials. The structure must withstand any increase of internal pressure on walls. Therefore it is required to account for that containment building is designed as a double wall as shown in Fig (1).

ii- External events: the design of the structures must take into account the protection against all possible external hazard effects such as (earthquakes, flooding, uplift ....). The nuclear power plant foundation was designed using case of such events with a thickness of a raft in the new generation design of 6.0 m (AREVA, 2009)

New generation nuclear power plant rafts represent a design challenge. These rafts have a thickness of $6.0 \mathrm{~m}$ with irregular cross shape as illustrated in fig.(4). Therefore analytical solution may be a difficult tool to determine the behavior of the raft (stress, deformations, and strains) and behavior of subsoil. This magnifies the importance of numerical analysis to study the soil-structure interaction for such important structures to achieve the highest level of accuracy. The failure of such rafts can cause dangerous effects on the environment such as leakage of radioactive materials.
Rapid development of computer technology has led to an increase the accuracy of geotechnical structure modeling with the use of advanced nonlinear constitutive models.

In this study, a 3D model for the new generation nuclear power plant was created using software ANSYS 13. A sensitivity analysis was conducted to assess the effect of soil elastic modulus and soil cohesion on the foundation behavior.

\section{CONTACT ELEMENT}

There are many models in the literature used to simulate soil-structure interaction. The following physical mathematical methods are widely used for soil structure interaction, among these:

a) Winkler subsoil model.

b) Elastic half space model.

These two models are elastic models which are not suitable to account for soil plastic behavior.

It is necessary to choose the suitable contact element for the numerical model when designing raft in order to compute the strains and stresses developed in the foundation. In ANSYS model there are two types of contact elements:

a) Node to node contact element (Conta52).

b) Surface to surface contact (Conta173) (ANSYS contact element guide, 2013).

Surface to surface contact element conta173 is used to represent the contact between two surfaces, one rigid surface and one deformable surface allowing sliding, and relative displacement between these elements as Fig.(2).

The use of concrete soil interaction contact element Conta173 is preferable for several reasons. Contact173 is suitable for the way of solution used in ANSYS. Either sparse direct method or precondition method. Conta173 transfers pressing forces as well as tension forces. The contact element allows for separation (gap between the two surfaces under tension that may develop) without creating numerical instability as in conta52 the surface conta173 model the whole surface 
behavior not only in single points (Malekova, et al., 2012)

\section{CONTROL CASE MODEL}

A 3D model of new generation nuclear plant is created using 144000 fine elements using ANSYS software for modeling of soil with depth $200 \mathrm{~m}$ and $300 \times 300 \mathrm{~m}$ in plan using Drucker-Prager soil model for rock as shown in Fig.(3). Raft with width of $102 \mathrm{~m}$ and length of $102 \mathrm{~m}$ with irregular shape is created with 638 elements shown in Fig.(4). Dimensions of raft footing in plan and footing thickness are fixed according to designer. The depth of soil is chosen as a result of sensitivity analysis. Many models were executed to compute settlement of soil at many depths. Depth of soil $=200 \mathrm{~m}$ was chosen based on vanishing of settlement (no settlement accrued below 200m). Containment building with height $52 \mathrm{~m}$ and $43 \mathrm{~m}$ diameter and thickness $1.3 \mathrm{~m}$ centered with raft is created with 3527 elements.

A dome with diameter of $43 \mathrm{~m}$ and height $21 \mathrm{~m}$ is created with 1224 elements. Elastic model was used to simulate elements of concrete structure.

Properties of control case model are as shown in Table (1).

Table (1) Properties of control case model.

\begin{tabular}{|c|c|c|}
\hline Properties & Raft & Rock soil \\
\hline $\begin{array}{c}\text { Modulus of } \\
\text { elasticity, E }\end{array}$ & $30.47 \mathrm{GN} / \mathrm{m}^{2}$. & $5.0 \mathrm{GN} / \mathrm{m}^{2}$. \\
\hline Density & $25 \mathrm{KN} / \mathrm{m}^{3}$. & $23 \mathrm{KN} / \mathrm{m}^{3}$. \\
\hline $\begin{array}{c}\text { Poisson's } \\
\text { ratio }\end{array}$ & 0.2 & 0.3 \\
\hline $\begin{array}{c}\text { characteristic } \\
\text { strength }\end{array}$ & $25 \mathrm{~N} / \mathrm{mm}^{2}$. & - \\
\hline Thickness & $6.0 \mathrm{~m}$ & - \\
\hline Cohesion, C & - & $8.0 \mathrm{MN} / \mathrm{m}^{2}$ \\
\hline $\begin{array}{c}\text { Friction angle, } \\
\phi\end{array}$ & - & $30^{\circ}$ \\
\hline
\end{tabular}

\subsection{Loads}

According to the designer company of the new generation of nuclear plant AREVA, the design characteristics will be as follows: $\mathrm{L} . \mathrm{L}=40 \mathrm{KN} / \mathrm{m}^{2}$ on all horizontal levels. Internal pressure $\mathrm{P}_{\mathrm{o}}=5 \mathrm{MN} / \mathrm{m}^{2}$. Pipe reaction during operation $=0.1 \mathrm{MN} / \mathrm{m}^{2}$.
Reaction of pipes when postulated does not exceed $1 \mathrm{MN} / \mathrm{m}^{2}$. Own weight of machines and equipment are tabulated in table (2):

Table (2) Own weight of equipment

\begin{tabular}{|c|c|}
\hline Steam generator & 800 tons (4 units). \\
\hline Pressurizer & 103 tons (4 units). \\
\hline Feeder frame & 40 tons. \\
\hline Reactivity unit & 43 tons. \\
\hline Fueling bridge & 64 tons. \\
\hline Containment liner & 200 tons. \\
\hline Pressure vessel & 600 tons. \\
\hline Fueling rods & 100 tons. \\
\hline Coolant pump & 500 tons (4 units). \\
\hline Moderator & 2000 tons. \\
\hline Fuel weight & 350 tons. \\
\hline Reactor weight & 395 tons. \\
\hline Water pump & 48 tons. \\
\hline
\end{tabular}

Cooling water tank $=1900$ tons divided into two tanks 950 tons each, one is the main cooling tank and the other is the reserved tank for emergency case (AREVA, 2010).

\subsection{Results of control case model}

The model was run using the loads mentioned before to compute the control results of the analysis. Fig. (5) Shows the contact stress under the raft from the analysis of control case model across section (1-1). The figure shows concentration of stresses calculated under the left side due to existence of feeding water tank which leads to unsymmetrical distribution of stress calculated under raft.

Maximum displacement of soil $(\delta)$ underneath the raft is found to be $-0.008 \mathrm{~m}$ $(8 \mathrm{~mm})$ under feeding water tank location. The maximum strain is found to be ($0.0011)$ at the same location.

Fig. (6) Contains the strain computed in the raft foundation with a maximum strain equals to -0.000383 under the feeding water tank.

\section{PARAMETRIC STUDY}

A parametric study was conducted to assess the effect of the key parameters on the model analyzed. In each model only one parameter is varied while keeping other parameters fixed.

\subsection{Influence of rock elastic modulus}

Ten runs were executed to compute the effect of rock elastic modulus with all parameters 
kept fixed and change only the rock elastic modulus (values from $0.05 \mathrm{GN} / \mathrm{m}^{2}$ to 500 $\mathrm{GN} / \mathrm{m}^{2}$ ). And then model was completed with increasing loads on raft till failure of soil. Fig.(7) indicates the effect of rock elastic modulus on the computed contact stress under nuclear power plant raft. The smaller the rock elastic modulus, the closer the contact stress distribution to the Navier stress distribution (simplified contact stress) under raft computed from (Eq.1) (Lars, 2000).

$\sigma_{i j}=\frac{N}{A} \pm \frac{M_{y} * x}{I_{y}}$

The increase in the rock elastic modulus results in an increase in the contact stress at the nuclear power plant edges and decrease in the contact stress at the middle of the raft.

Interestingly, in Fig.(7) the effect of the increase of the applied stress on the raft for the control case model until contact stress reaches failure. The contact stress distribution under the raft due to failure is shown in Fig.(7). The contact stress at failure was found to be higher at the middle and less at edges due to the less confinement (normal stresses at edges).

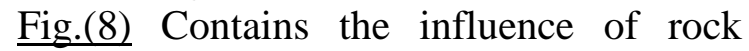
elastic modulus on the maximum stress computed in the rock. It is found that the higher the rock modulus, the lower the stress developed in the rock mass beneath the raft. While the maximum displacement of the rock beneath the raft decreases with the increase of the rock modulus as shown in Fig. (9).

Similarly, the decrease of maximum elastic strain developed in rock has been noticed due to the increase of rock elastic modulus as shown in Fig. (10).

Decrease of maximum stress developed in raft with the increase of soil elastic modulus was computed in the raft due to decrease of soil strain and consequently the concrete strain decrease due to soilstructure interaction. Concrete elastic modulus is constant. So decrease of stress in raft is occurred as shown in Fig.(11).

\subsection{Influence of rock cohesion}

To compute the effect of rock cohesion, all parameters of control case model are kept fixed and decrease rock soil cohesion to be $\left(\mathrm{C}=10 \mathrm{KN} / \mathrm{m}^{2}\right)$, and run the model, Fig. (12) Indicates that the contact stress of rock under raft behaves different than the control case. Due to the decrease of rock cohesion rock behaves like loose soil. As it is known that very poor rock contains about 20\% clay (Mathis, et al., 1995). Failure zones occurred at the edges of raft (tension zones). The stress at the center of the raft is higher than edges unlike the control case model. Fig.(12) clarify the contact stress of rock with cohesion $\mathrm{C}=10$ $\mathrm{KN} / \mathrm{m}^{2}$ compared to contact stress of control case model and Navier stress.

\subsection{Influence of raft elastic modulus}

Eight cases were executed to calculate the effect of changing raft elastic modulus (by increasing concrete characteristic strength from $25 \mathrm{~N} / \mathrm{mm}^{2}$ to $60 \mathrm{~N} / \mathrm{mm}^{2}$ ) and keep all of the parameters fixed Fig.(13) contains that change of concrete characteristic strength of raft has minimal effect decreasing of the contact stress distribution under raft. This small effect can be explained from the flexural rigidity of the raft footing:

$\mathrm{D}=\frac{E_{c} * t^{3}}{12\left(1-v^{2}\right)}$

(Timoshenko, et al., 1959)

Where: $E_{c}$ is concrete elastic modulus function of concrete strength.

$\mathrm{t}$ : is footing thickness $=6 \mathrm{~m}$.

$v:$ is poisson's ratio of concrete $=0.2$

Change of $\mathrm{D}$ with concrete strength is clarified in Table (3).

Table (3) values of flexural rigidity with concrete strength:

\begin{tabular}{|c|c|c|}
\hline $\mathrm{F}_{\mathrm{cu}}\left(\mathrm{N} / \mathrm{mm}^{2}\right)$ & $\mathrm{E}_{\mathrm{c}}\left(\mathrm{GN} / \mathrm{m}^{2}\right)$ & $\mathrm{D}(\mathrm{GN} . \mathrm{m})$ \\
\hline 25 & 30.5 & 571.35 \\
\hline 30 & 31.9 & 598.85 \\
\hline 35 & 33.3 & 624.03 \\
\hline 40 & 34.5 & 647.34 \\
\hline 45 & 35.7 & 669.09 \\
\hline 50 & 36.8 & 689.5 \\
\hline 55 & 37.8 & 708.76 \\
\hline 60 & 38.8 & 727.05 \\
\hline
\end{tabular}


table (3) shows that effect of increasing concrete strength on rigidity is small and due to this increase a small decrease of raft strain is occurred. As a result the contact stress of soil is decreasing as illustrated in Fig.(13).

\subsection{Influence of raft thickness}

In this analysis, the raft thickness of raft is changed while keeping all other parameters of the control case fixed. Fig. (14) contains the contact stress of rock under raft changing the raft thickness, Fig.(14) illustrates that if raft thickness decreased to $5 \mathrm{~m}$ and refer to equation (2) the rigidity decreases to be (331.35GN.m) and the strain of raft increases while this $1 \mathrm{~m}$ decrease of thickness does not affect the total stress of structure due to the big area of raft. It is clear that soil failed for raft thickness less than $6 \mathrm{~m}$ because the stress of soil increased due to decrease of raft strain and exceeded the maximum bearing capacity $\left(10 \mathrm{MN} / \mathrm{m}^{2}\right)$.

From this result it is clear that the BS-8110 recommendation of raft footing design for thickness to be $6.0 \mathrm{~m}$ is very adequate.

\section{SUMMARY AND CONCLUSION}

The following conclusions can be drawn from the analysis:

1. Maximum strain of raft for the control case over rock soil is very low and less than the limits of British standards- 8110 for concrete sections (0.0035) which is acceptable.

2. Sensitivity analysis shows that lowering cohesion of rock soil results in dramatic change in contact stress computed under the raft similar to loose soil and may lead to failure of soil under raft.

3. Sensitivity analysis shows that decrease of soil elastic modulus of rock soil may lead to failure of soil under the raft.

4. The effect of concrete characteristic strength change on the nuclear power plant was minimal in the models analyzed.

5. Sensitivity analysis shows that decrease of raft thickness less than $6.0 \mathrm{~m}$ may lead to failure of soil under the raft.

\section{REFERENCES}

AREVA EPR4-New generation of reactorsThe most advanced reactors in operation [Online]. - 2009. - www.AREVA.com.

AREVA New generation of nuclear power plants $1600 \mathrm{MW}$ Reactors [Online] // Areva company. - 2010. - www.AREVA.com.

Lars Damkild Stress and stiffness analysis of structures [Book]. - Dk.Lyngby: Department of structural engineering and materials technical university of Denmark, 2000. - Vol. chapter2.

Malekova V and Jendzelovsky Ch An analysis of contact element of foundation structures [Journal] // Mechanical engineering. - 2012. - No.7.

Mathis J I and Page C $\mathbf{H}$ Drifting in very poor rock experience and analysis [Journal]. Washington: Annual northwest minning association convention, 1995.

Timoshenko $\mathbf{S}$ and Woinowsky $S$ Krieger Theory of plates and shells [Book] = Bending analysis of plates. - 1959. - second: Vol. chapter1 : pp. 1-33. 


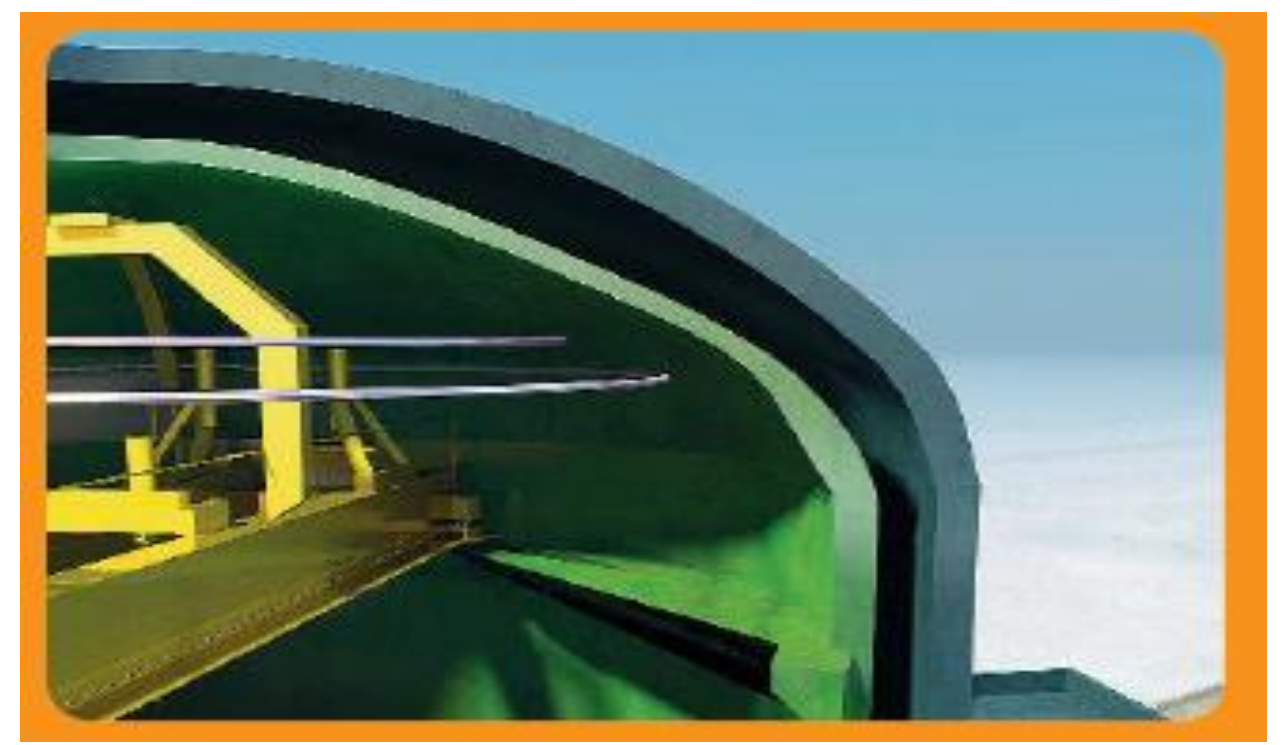

Fig. (1) Double wall of new generation of nuclear plants (www.AREVA.com)

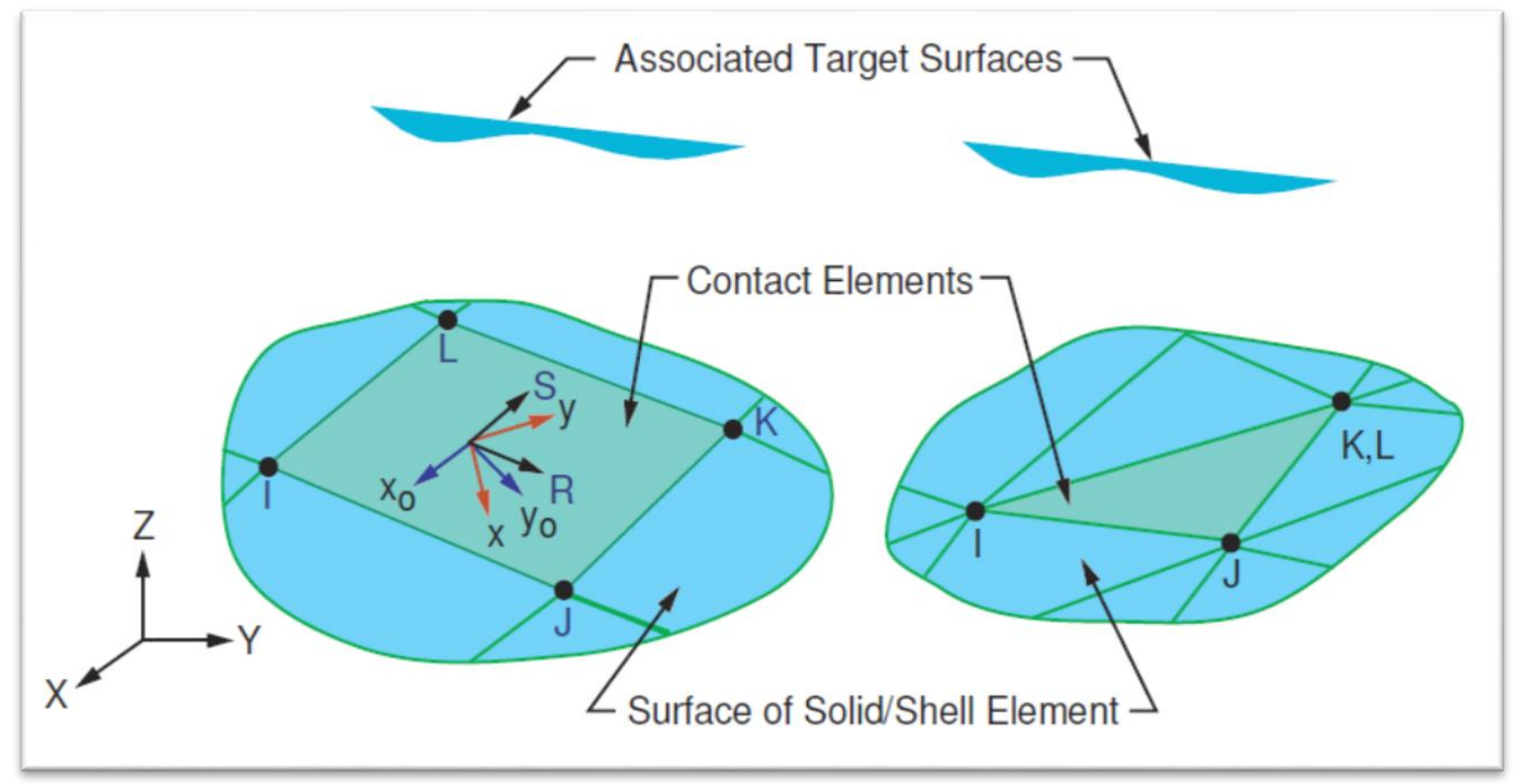

Fig. (2) Contact element (conta173) and target element (targ170) (ANSYS -V.13) 


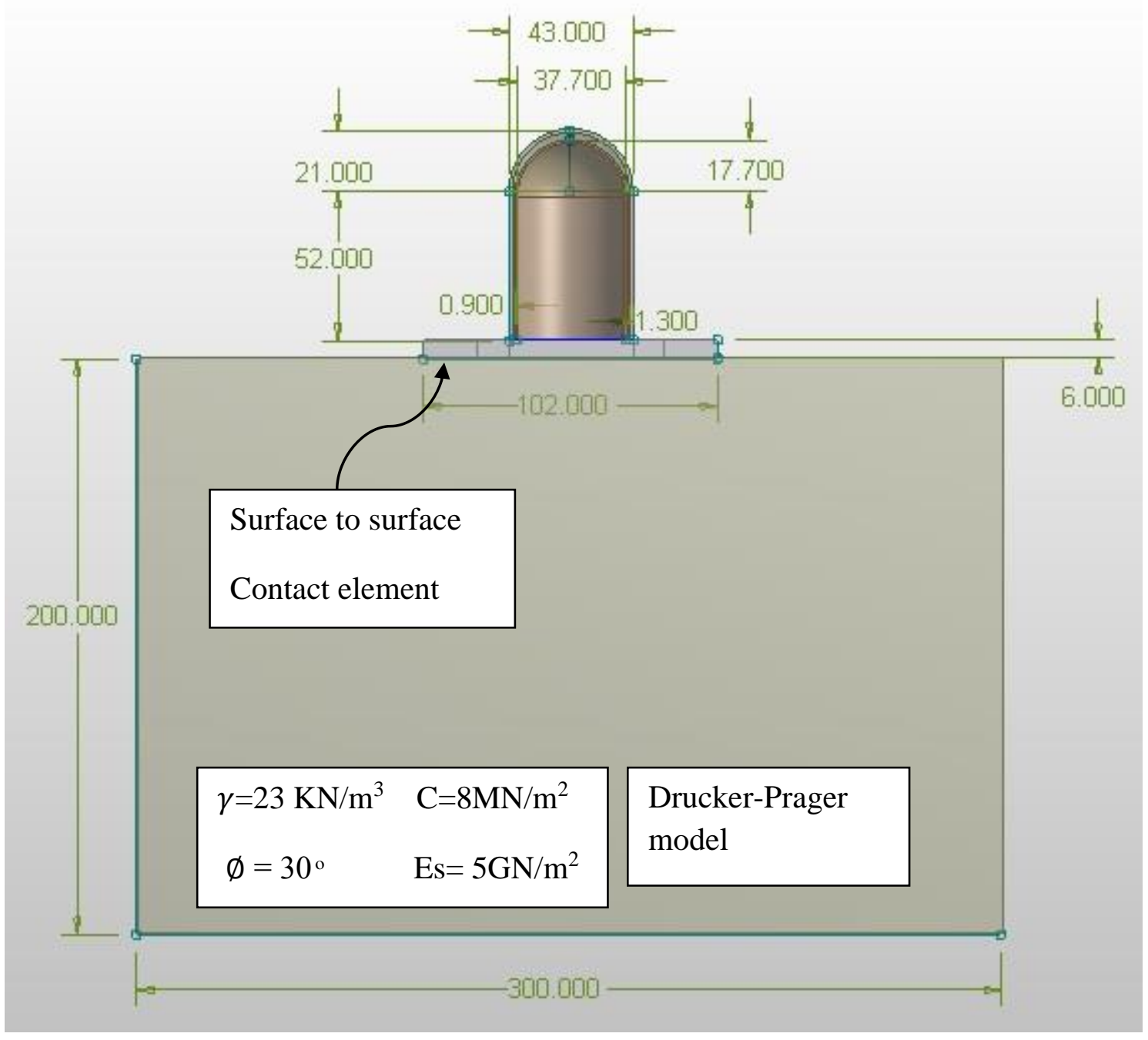

Fig (3) Geometry of the model of nuclear power plant showing the containment building. 


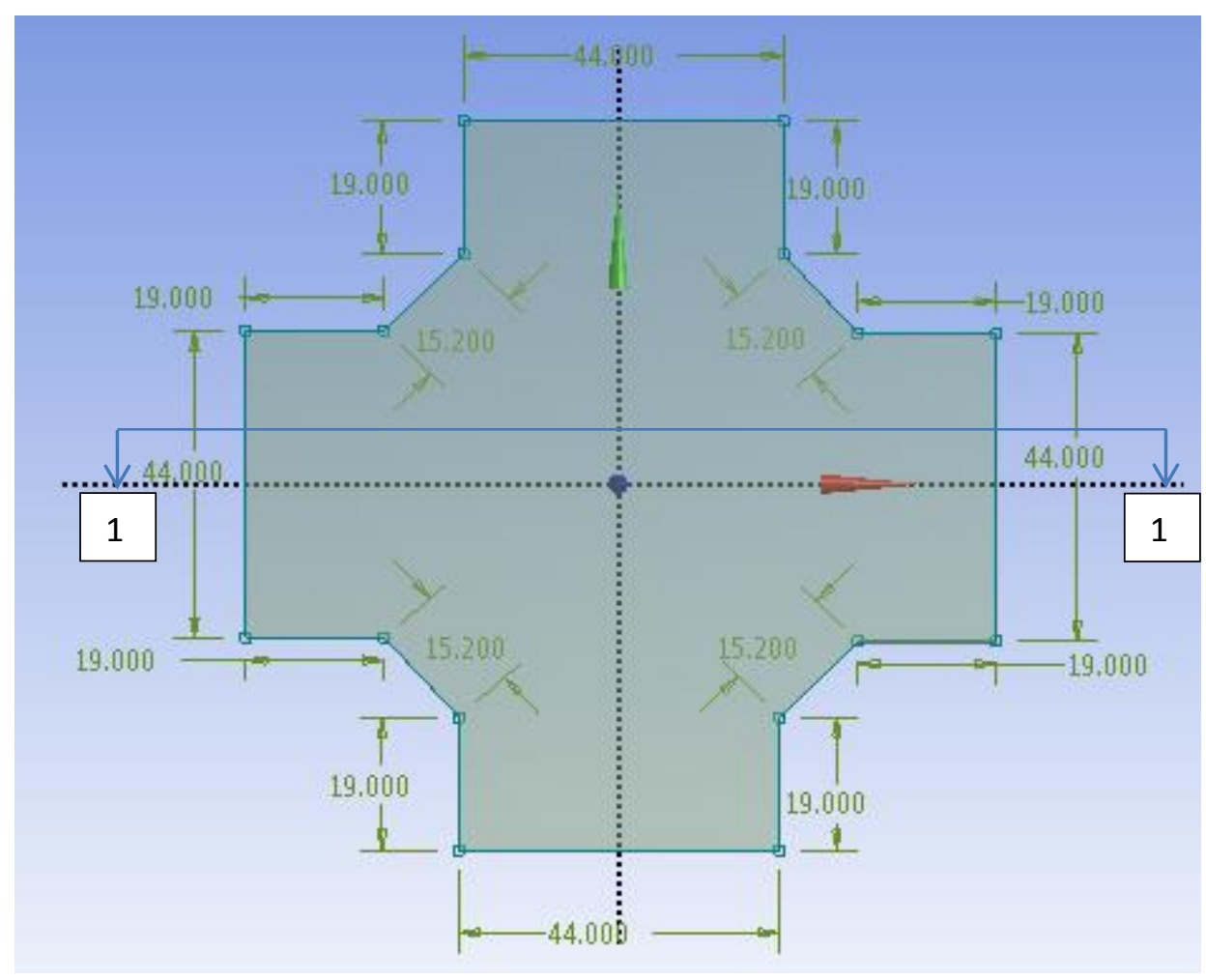

Fig (4) Irregular shape raft footing in plane view.

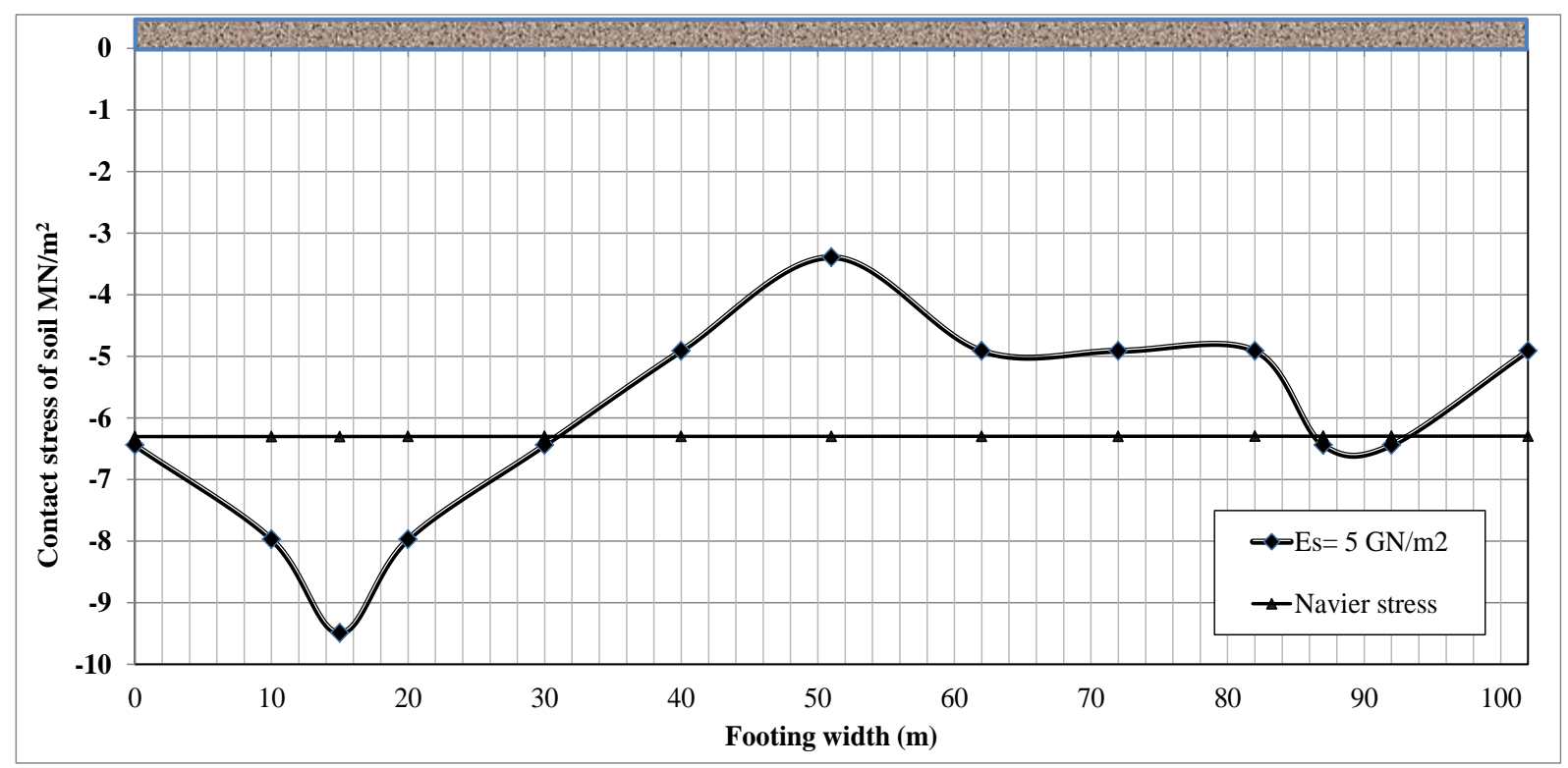

Fig (5) Contact vertical stress of control case model across section (1-1). 


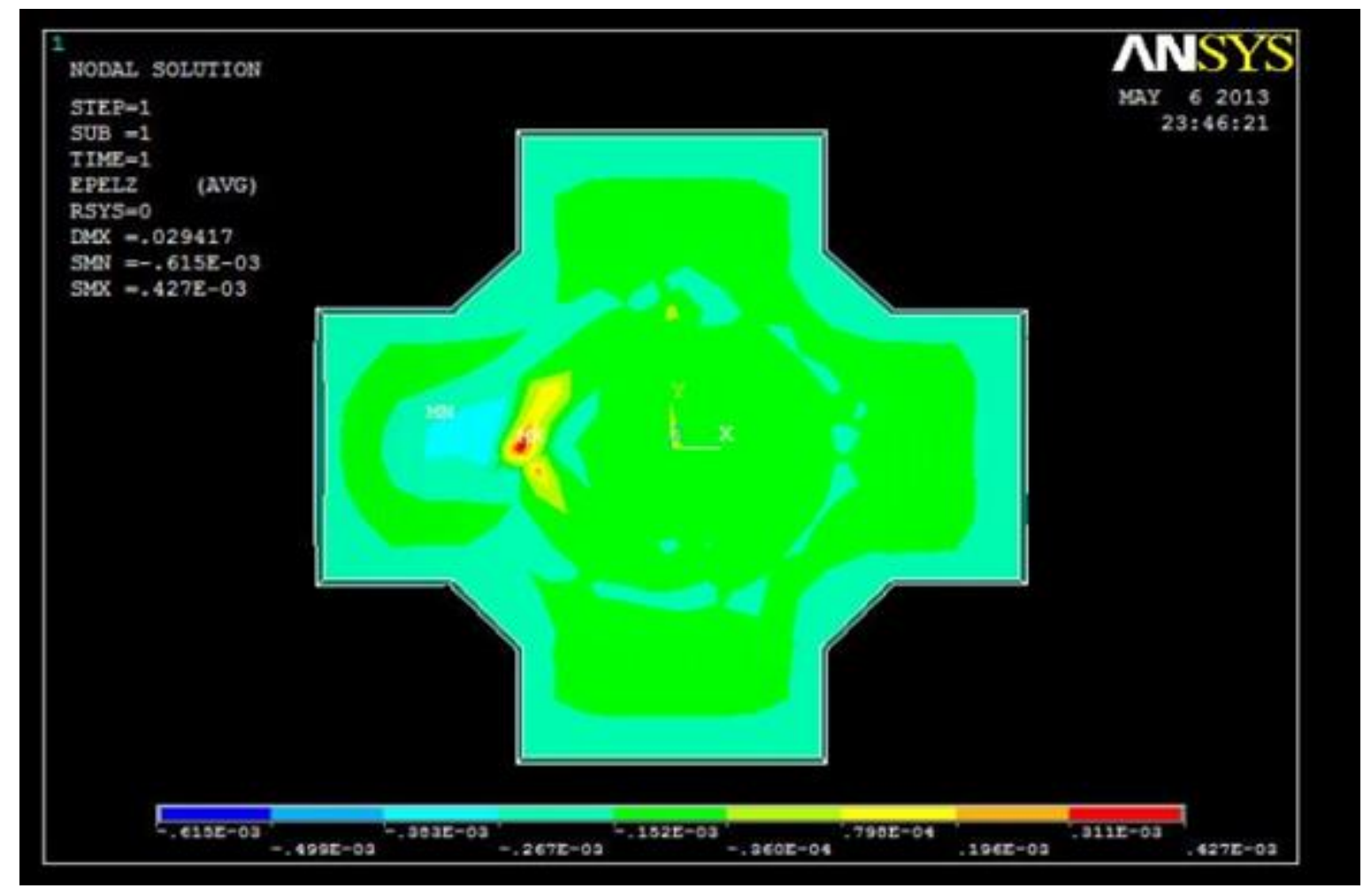

Fig (6) Plan view of the raft showing the strain computed in footing.

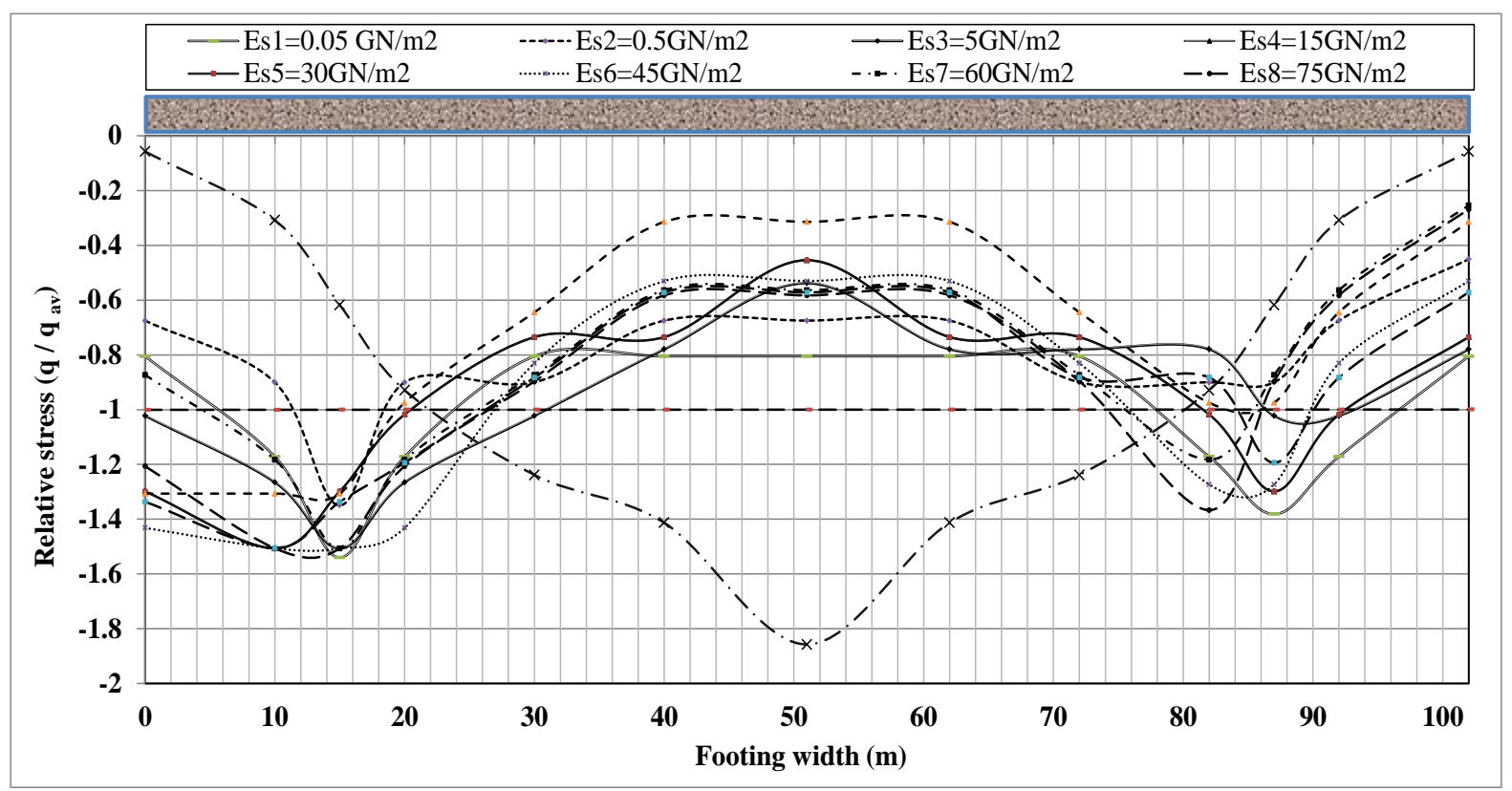

Fig (7) Influence of soil elastic modulus on contact stress of soil. 




Fig (8) Influence of soil elastic modulus on the calculated maximum stress in soil.

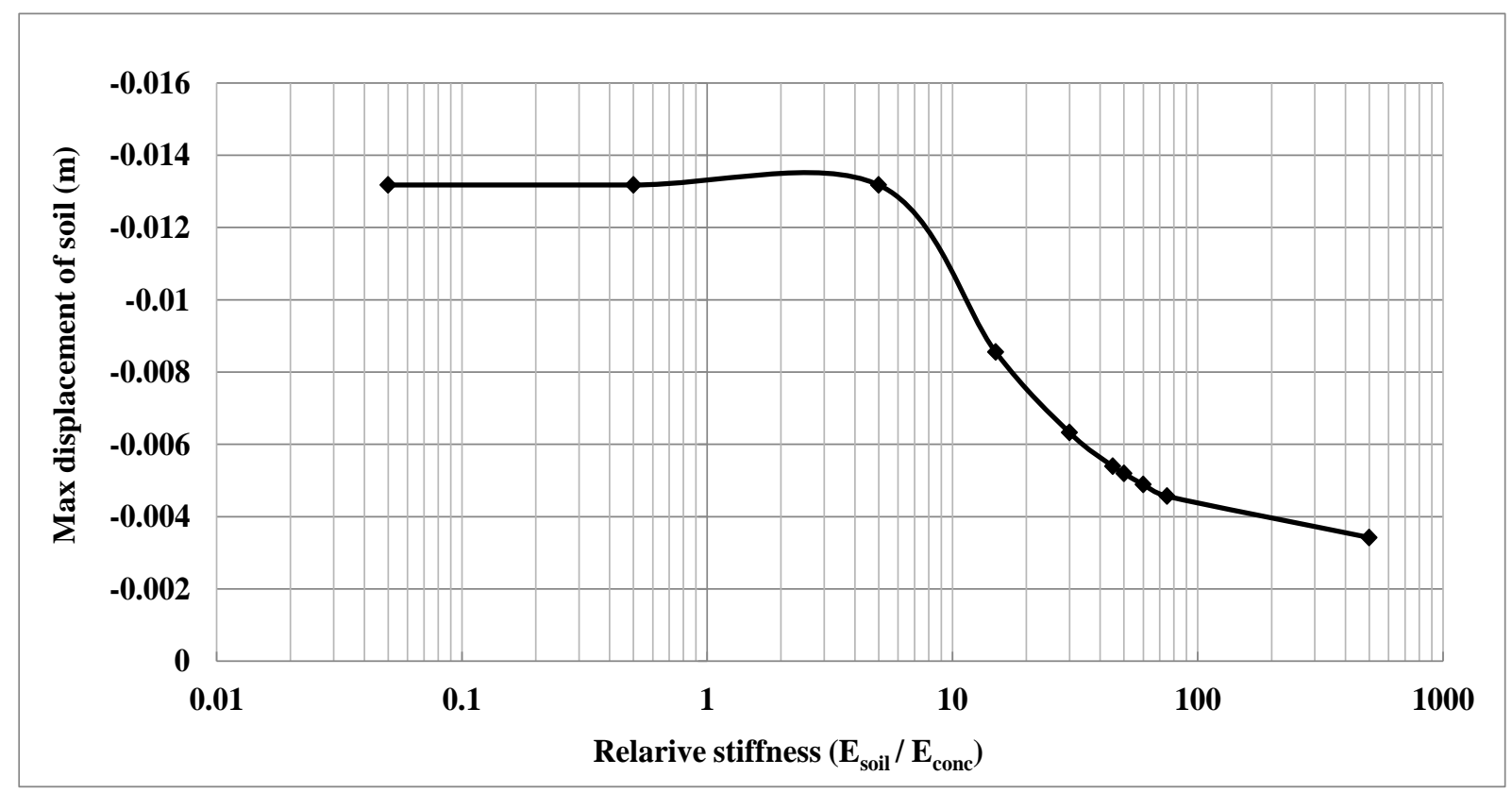

Fig (9) Influence of soil elastic modulus on maximum displacement of soil. 


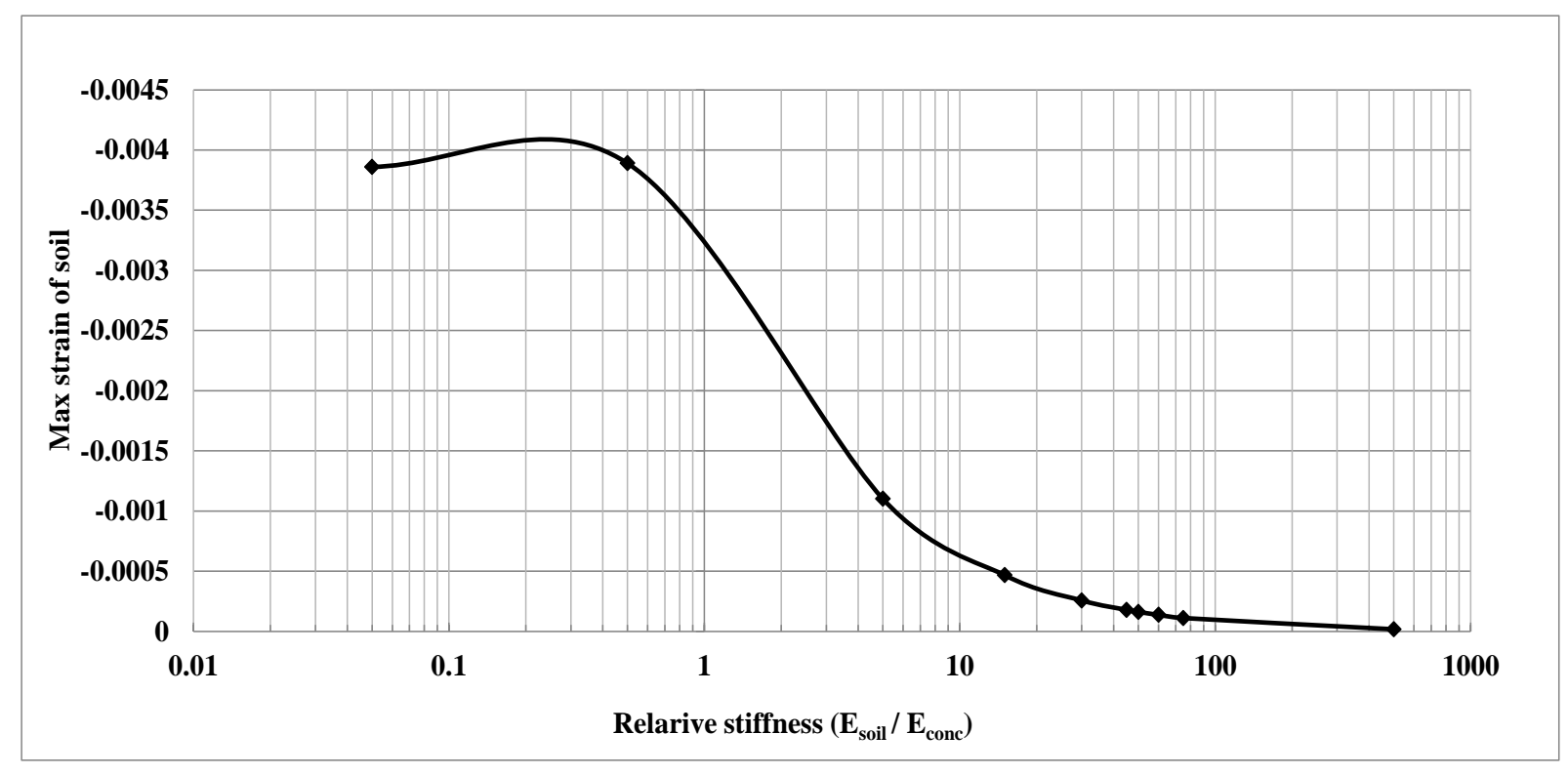

Fig (10) Influence of soil elastic modulus on elastic strain of soil.

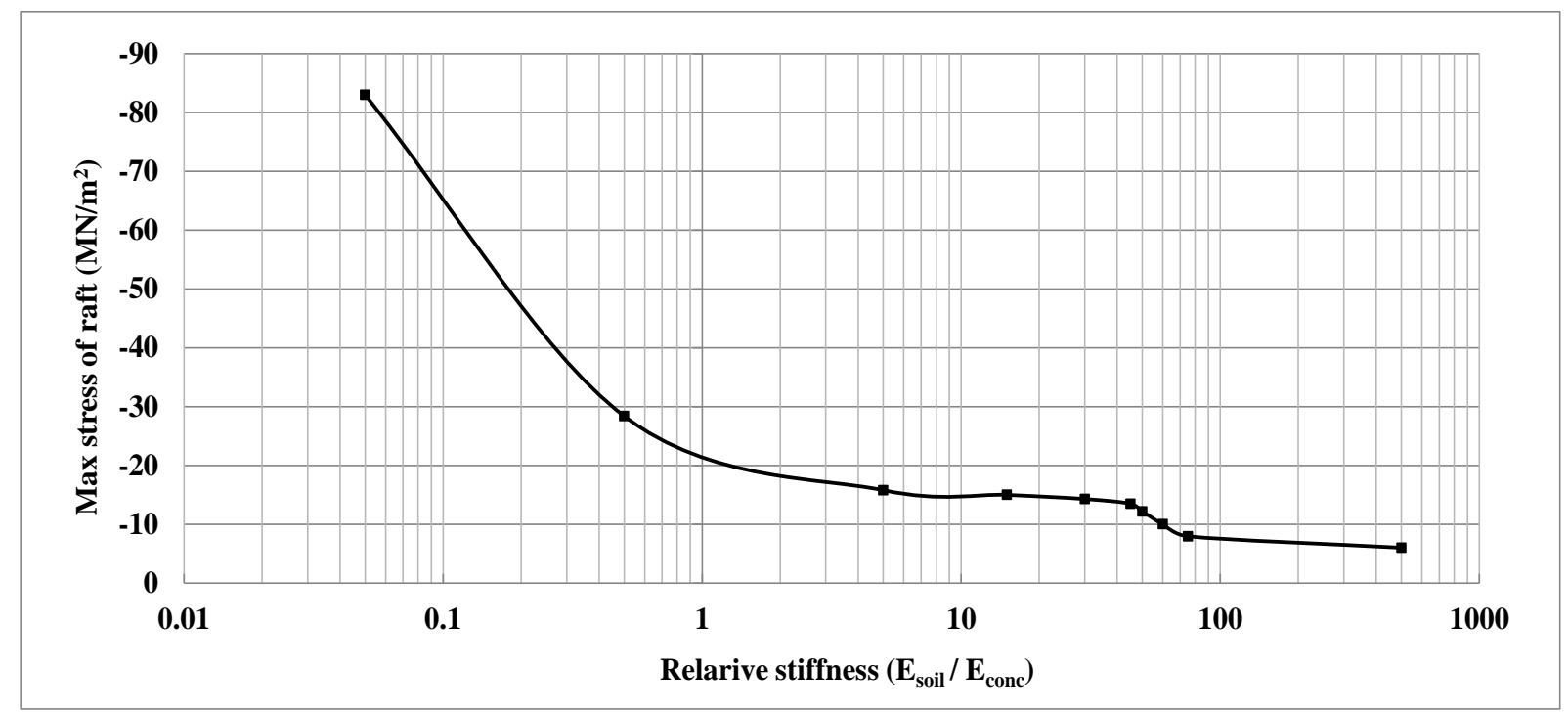

Fig (11) Influence of soil elastic modulus on maximum stress of raft. 


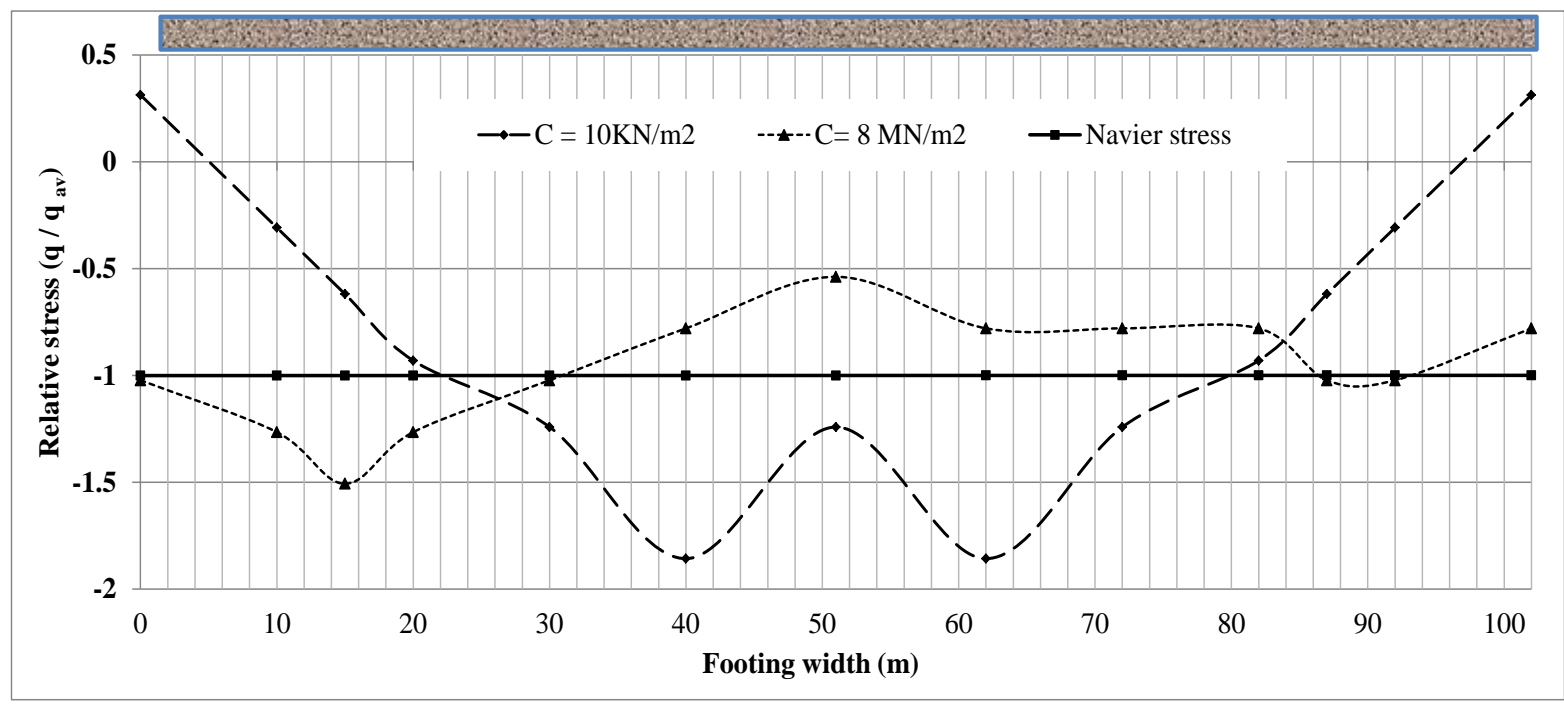

Fig (12) Influence of soil elastic modulus on contact stress under footing for rock with cohesion $\left(\mathrm{C}=10 \mathrm{KN} / \mathrm{m}^{2}\right)$.

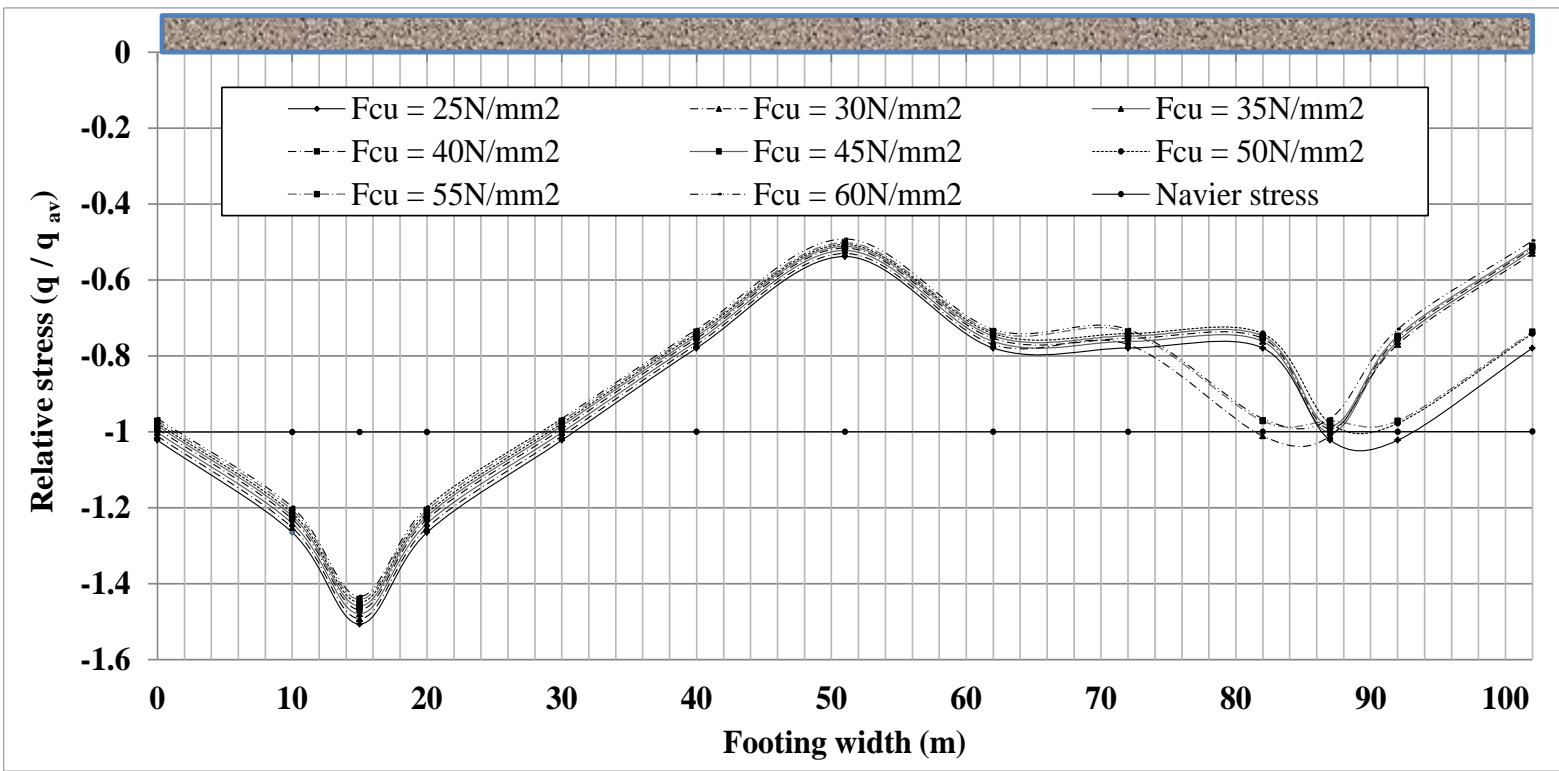

Fig (13) Influence of concrete characteristic strength of footing on contact stress of soil. 




Fig (14) Influence of footing thickness on contact stress under footing. 